\title{
Correction: Extracting viscoelastic material parameters using an atomic force microscope and static force spectroscopy
}

\author{
Cameron H. Parvini, M. A. S. R. Saadi and Santiago D. Solares*
}

\section{Correction}

Address:

Department of Mechanical and Aerospace Engineering, The George Washington University School of Engineering and Applied Science, 800 22nd St. NW, Suite 3000, Washington, DC 20052, United States

Email:

Santiago D. Solares* - ssolares@gwu.edu

* Corresponding author

Keywords:

atomic force microscopy (AFM); creep; force mapping; indentation; Kelvin-Voigt; static force spectroscopy (SFS); viscoelasticity
Beilstein J. Nanotechnol. 2021, 12, 137-138.

https://doi.org/10.3762/bjnano.12.10

Received: 04 January 2021

Accepted: 21 January 2021

Published: 28 January 2021

Editor-in-Chief: T. Schimmel

(C) 2021 Parvini et al.; licensee Beilstein-Institut. License and terms: see end of document.

This correction refers to Beilstein J. Nanotechnol. 2020, 11, 922-937. doi:10.3762/bjnano.11.77

In the "Useful Viscoelastic Quantities" section of the original publication, it is stated that the storage modulus $\left(E^{\prime}\right)$ and storage compliance $\left(J^{\prime}\right)$ are inverses of one another (Equation 10). Similarly, it is stated that the loss modulus $\left(E^{\prime \prime}\right)$ and loss compliance $\left(J^{\prime \prime}\right)$ are inverses of one another (Equation 11). However, it is the relaxance $(Q)$ and retardance $(U)$ that are inverses of one another in the Laplace domain (not in the time domain), leading to a more complex relationship between the moduli and their respective compliances. Translation between harmonic quantities can be accomplished through the expressions below, where $\tilde{E}$ is the absolute modulus and $\widetilde{J}$ is the absolute compliance [1]:

$$
\begin{aligned}
& E^{\prime}(\omega)=\frac{J^{\prime}(\omega)}{\tilde{J}(\omega)^{2}}, \\
& E^{\prime \prime}(\omega)=\frac{J^{\prime \prime}(\omega)}{\tilde{J}(\omega)^{2}},
\end{aligned}
$$

$$
\begin{aligned}
& J^{\prime}(\omega)=\frac{E^{\prime}(\omega)}{\tilde{E}(\omega)^{2}}, \\
& J^{\prime \prime}(\omega)=\frac{E^{\prime \prime}(\omega)}{\tilde{E}(\omega)^{2}} .
\end{aligned}
$$

Absolute modulus and absolute compliance are calculated as: 
The leftmost term in Equation 10 and Equation 11 in the original manuscript is thus incorrect and needs to be removed, leaving the following corrected expressions:

Equation 10:

$$
J^{\prime}(\omega)=J_{g}+\sum_{i=1}^{n}\left(\frac{J_{n}}{1+\tau_{n}^{2} \omega^{2}}\right)
$$

Equation 11:

$$
J^{\prime \prime}(\omega)=\sum_{i=1}^{n}\left(\frac{J_{n} \tau_{n} \omega}{1+\tau_{n}^{2} \omega^{2}}\right)
$$

\section{ORCID ${ }^{\circledR}$ iDs}

M. A. S. R. Saadi - https://orcid.org/0000-0002-8763-1512

Santiago D. Solares - https://orcid.org/0000-0003-0895-8160

\section{Reference}

1. Tschoegl, N. W. The Phenomenological Theory of Linear Viscoelastic Behavior; Springer: Berlin Heidelberg, Germany, 1989.

doi:10.1007/978-3-642-73602-5

\section{License and Terms}

This is an Open Access article under the terms of the Creative Commons Attribution License (https://creativecommons.org/licenses/by/4.0). Please note that the reuse, redistribution and reproduction in particular requires that the author(s) and source are credited and that individual graphics may be subject to special legal provisions.

The license is subject to the Beilstein Journal of Nanotechnology terms and conditions:

(https://www.beilstein-journals.org/bjnano/terms)

The definitive version of this article is the electronic one which can be found at:

https://doi.org/10.3762/bjnano.12.10 